\title{
HARMONIC ELIMINATION AND DC SOURCE EQUALIZATION IN THREE-PHASE ASYMMETRIC CASCADED MLI
}

\author{
Dr.R.Seyezhai*, K.Radhasree**, K.Sivapathy** \& Vardhaman** \\ *Associate Professor, ** Final Year Students \\ Department of EEE, SSN College of Engineering, Chennai, India.
}

\begin{abstract}
In recent years, multilevel inverters are extensively employed in high power industrial applications. This paper focuses on asymmetric MultiLevel Inverter (MLI) with reduced number of DC sources. The performance of the inverter is improved by incorporating Selective Harmonic Elimination. The focus has been laid on the fifth and seventh order harmonics as they are responsible for the torque ripples in the case of induction motor drives. Also, the impact of change in magnitude of the DC sources on the harmonics is also analyzed and the results are validated. The multilevel inverter output with reduced Total Harmonic Distortion (THD) is used to drive a resistive load . The simulation is carried out in MATLAB/Simulink.
\end{abstract}

Keywords: - Asymmetric MLI, Harmonic elimination \& DC source equalization

\section{I.INTRODUCTION}

In this paper, a multilevel inverter with two unequal DC sources is studied [1]. The selective harmonic elimination switching scheme is used to control the needed power electronic devices. A method is presented where the switching angles are computed such that a desired fundamental sinusoidal voltage is produced while at the same time certain higher order harmonics are eliminated. Using the idea of Fourier series, the equations eliminating certain harmonics were derived in terms of the switching angles. These equations are transcendental equations. By making some simple substitutions, these transcendental equations were transformed into polynomial equations. After forming these polynomial equations, resultant theory was used to solve the polynomial equations [3,4]. Using Mathematica, the aforementioned equations were derived and solved to find the switching angles. In this paper, two unequal DC sources are used to produce seven level AC output voltage. DC source equalization is carried out and it gives an idea about the change in the magnitude of the higher order harmonics with the change in magnitude of the DC sources involved. The performance of asymmetric cascaded MLI with R-load is studied by applying selective harmonic elimination and the results are validated.

\section{ASYMMETRIC CASCADED MULTILEVEL INVERTER}

The cascaded H-bridges multilevel inverter introduces the idea of using separate DC sources to produce an AC voltage waveform. Each H-bridge inverter is connected to its own DC source $\mathrm{V}_{\mathrm{dc}}$. By cascading the AC outputs of each $\mathrm{H}$ bridge inverter, an $\mathrm{AC}$ voltage waveform is produced. In a symmetric multilevel inverter, to produce seven level output voltage, three equal DC sources are required. Hence as the number level increases, number H-bridges also increases. This may increase the cost. Hence to reduce the number of $\mathrm{H}$-bridges, a multilevel inverter with unequal DC sources in constructed.

Figure 1 provides the illustration of asymmetric multilevel inverter with two $\mathrm{H}$-bridges each one connected to the DC source $\mathrm{V}_{\mathrm{dc}}$ and $0.5 \mathrm{Vdc}$. The output voltage of the first $\mathrm{H}$ bridge is denoted by $\mathrm{v}_{1}$ and the output of the second $\mathrm{H}$ bridge is denoted by $\mathrm{v}_{2}$ so that the output of this two DC source cascade multilevel inverter is $v(t)=v_{1}(t)+v_{2}(t)$.

By opening and closing the switches of $\mathrm{H}_{1}$ appropriately, the output voltage $\mathrm{v}_{1}$ can be made equal to $-\mathrm{V}_{\mathrm{dc}}, 0$, or $\mathrm{V}_{\mathrm{dc}}$ while the output voltage of $\mathrm{H}_{2}$ can be made equal to $\mathrm{V}_{\mathrm{dc}} / 2,0$, or $\mathrm{V}_{\mathrm{dc}} / 2$ by opening and closing its switches appropriately. Therefore, the output voltage of the inverter can have the values $-3 \mathrm{~V}_{\mathrm{dc}} / 2,-\mathrm{V}_{\mathrm{dc}},-\mathrm{V}_{\mathrm{dc}} / 2,0, \mathrm{~V}_{\mathrm{dc}} / 2, \mathrm{~V}_{\mathrm{dc}}$, $3 \mathrm{~V}_{\mathrm{dc}} / 2$, which is seven levels and is illustrated in Figure $2 \&$ 
Table -I.

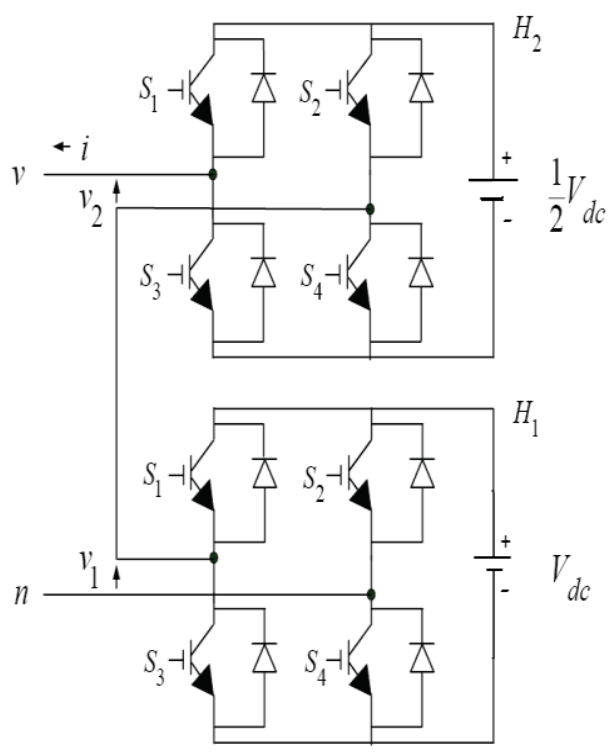

Fig.1. Asymmetric Cascaded Multilevel Inverter

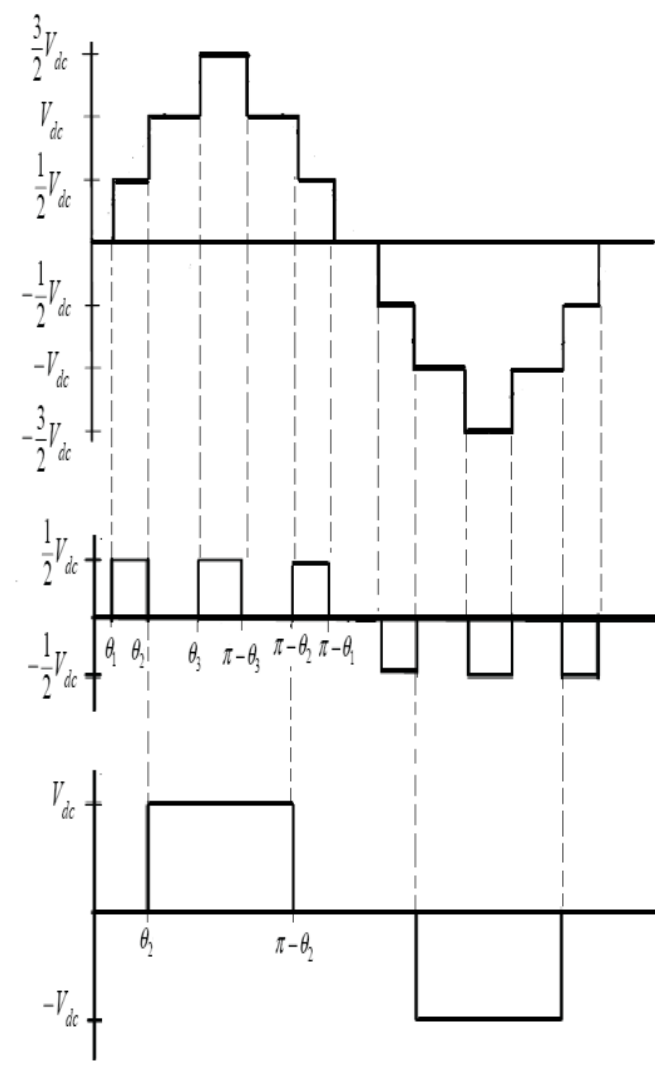

Figure 2. Output waveform of seven level asymmetric multilevel inverter

TABLE I: Switching Angle for MLI

\begin{tabular}{|l|l|l|l|}
\hline $\boldsymbol{\theta}$ & $\mathbf{V 1}$ & $\mathbf{V 2}$ & $\mathbf{V}=\mathbf{V 1}+$ \\
\hline $0 \leq \theta \leq \theta 1$ & 0 & 0 & 0 \\
\hline $\begin{array}{l}\theta 1 \leq \theta \leq \\
\theta 2\end{array}$ & 0 & $\mathrm{Vdc} / 2$ & $\mathrm{Vdc} / 2$ \\
\hline $\begin{array}{l}\theta 2 \leq \theta \leq \\
\theta 3\end{array}$ & $\mathrm{Vdc}$ & 0 & $\mathrm{Vdc}$ \\
\hline $\begin{array}{l}\theta 3 \leq \theta \leq \\
\pi / 2\end{array}$ & $\mathrm{Vdc}$ & $\mathrm{Vdc} / 2$ & $3 \mathrm{Vdc} / 2$ \\
\hline
\end{tabular}

III.HARMONIC ELIMINATION SCHEME

Selective harmonic elimination method is used to eliminate the specified harmonics in the output voltage. The elimination of low-order harmonics is an important issue in drive applications. When high switching efficiency is of utmost importance, it is desirable to keep the switching frequency as low as possible. For a given fundamental output voltage theoretically, the switching angles that produce the fundamental while not generating specifically 
chosen harmonics can be found. The switching angles corresponding to each level is shown in Fig.2. Switching angles can be computed by converting the transcendental equations that specify the elimination of the harmonics into an equivalent set of polynomial equations [5,6]. Then using, the mathematical theory of resultants or the mathematical software such as MathCAD or Mathematica [7], solution to these polynomial equations can be found. Applying Fourier theory to the output voltage waveform of multilevel converters, which is odd quarter-wave symmetric, we can find the Fourier expression of the multilevel output voltage as

$\left.V(t)=\sum_{n=13, S_{n}, 5_{n}}^{\infty}\left[\frac{4}{n \pi\left(V_{1} \cos \left(n \theta_{1}\right)+V_{2}\right]} \cos \left(n \theta_{2}\right)+\cdots+V_{8} \cos \Omega\left(n \theta_{8}\right]\right)\right) \sin (n \omega t)$

If the DC voltages are equal in the multilevel converter, the equation for the fundamental frequency switching control method can be expressed as:

$\left.V(t)=\sum_{n=1,3,5_{m,}}^{\infty} \llbracket \frac{4 V_{D C}}{n \pi\left(\cos \left(n \theta_{1}\right)+\rrbracket\right.} \cos \left(n \theta_{2}\right)+\cdots+\cos \llbracket\left(n \theta_{\Omega} \rrbracket\right)\right) \sin (n \omega t)$

From the equation, it can be seen that the output voltage has no even harmonics because the output voltage waveform is odd quarter-wave symmetric. It also can be seen from above equation that the peak values of these odd harmonics are expressed in terms of the switching angles $\theta_{1}, \theta_{2}$ and $\theta_{\mathrm{s} .}$. Furthermore, the harmonic equations produced from the above equations are called as transcendental equations.

If one wants to eliminate the $\mathrm{n}^{\text {th }}$ harmonic, then that means to choose a series of switching angles to let the value of the $\mathrm{n}^{\text {th }}$ harmonic be zero. Therefore, an equation with $\mathrm{s}$ switching angles will be used to control the $\mathrm{s}$ different harmonic values. Generally, an equation with s switching angles is used to determine the fundamental frequency value, and to eliminate s- 1 low order harmonics $[8,9]$. For example, for an equation with three switching angles, the above equation becomes

$\left.V(t)=\sum_{n=1,3,5, \ldots}^{\infty} \llbracket \frac{4 V_{D C}}{n \pi\left(\cos \left(n \theta_{1}\right)+\rrbracket\right.} \cos \left(n \theta_{2}\right)+\cos \rrbracket\left(n \theta_{3} \rrbracket\right)\right) \sin (n \omega t)$

Here, the fundamental peak value of the output voltage of $\mathrm{V}_{1}$ should be controlled, and the $5^{\text {th }}$ and $7^{\text {th }}$ order harmonics should be eliminated. The resulting harmonic equations (4) to (6) are given below:

$$
\begin{aligned}
& \cos \llbracket\left(\theta_{1}\right)+\cos \left(\theta_{2}\right)+\cos \left(\theta_{3} \rrbracket\right)=m \\
& \cos \rrbracket\left(5 \theta_{1}\right)+\cos \left(5 \theta_{2}\right)+\cos \left(5 \theta_{3} \rrbracket\right)=\mathbf{0}
\end{aligned}
$$

(5)

$$
\cos \llbracket\left(7 \theta_{1}\right)+\cos \left(7 \theta_{2}\right)+\cos \left(7 \theta_{3} \rrbracket\right)=0
$$

Where $\mathrm{m}=\pi \mathrm{V}_{1} / 4 \mathrm{~V}_{\text {dc. }}$. For 7-level inverter $\mathrm{m}$ is calculated as 1.18. Here, the third harmonic has not been eliminated because the triple-n harmonics can be automatically cancelled in the line-line voltages for balanced three-phase systems. Therefore, the triplen harmonics are not chosen for elimination in the phase voltage. The above equations are difficult to solve without using some sort of numerical iterative technique, such as Newton Raphson's method. However, by making some simple changes of variables and simplifying, these transcendental equations can be transformed into a set of polynomial equations. Then, the resultant theory can be utilized to find all solutions to the harmonic equations theoretically or the solutions can be simulated by software 10,11$]$.

Solutions to the Harmonic Equations by MathCAD using Trigonometric identities are given in equations (7) to (12).

$\cos (5 \theta)=5 \cos (\theta)-20 \cos ^{3}(\theta)+16 \cos ^{5}(\theta)$

(7)

$\cos (7 \theta)=-7 \cos (\theta)+56 \cos ^{3}(\theta)-112 \cos ^{5}(\theta)+64 \cos ^{7}(\theta)$

And changing the variables as

$$
\begin{aligned}
& x_{1}=\cos \llbracket\left(\theta_{1} \rrbracket\right) \\
& x_{2}=\cos \llbracket\left(\theta_{2} \rrbracket\right)
\end{aligned}
$$

And

$$
x_{s}=\cos \llbracket\left(\theta_{s} \rrbracket\right)
$$

The harmonic equations for 7-level inverter can be written as

$$
p_{5}\left(x_{1}, x_{2}, x_{3}\right)=\sum_{n=1}^{\mathbf{3}} \llbracket\left(5 x_{n} \rrbracket-20 x_{n}^{3}+16 x_{n}^{5}\right)=0
$$

These equations are simulated in MathCAD and we get following switching angles when $\mathrm{m}$ is approximated to 1.32 .

$\theta_{1}=39.651^{\circ}, \theta_{2}=61.388^{\circ} \& \theta_{3}=85.918^{\circ}$. 
From simulation results it can also be concluded that the modulation index $\mathrm{m}$ has solutions only when $\mathrm{m}$ is in the range of 1.18 to 2.5 for a seven level output... For some modulation indices, there are more than one solution set. The THD is different for different solution sets; therefore, the low THD Solution set should be chosen for practical application. Solution is not continuous for some modulation indices $\mathrm{m}$. One disadvantage of the fundamental frequency switching control is its narrow modulation index range.

\section{DC SOURCE EQUALIZATION}

DC source equalization gives an idea about the change in the magnitude of the higher order harmonics with the change in magnitude of the DC sources involved. The cascaded multilevel inverter with two unequal sources can be represented as shown in equation .13 .

$V_{k}=\frac{4}{\pi} *\left[E_{1} * \cos \left(k \theta_{1}\right)+E_{2} * \cos \left(k \theta_{2}\right)+\left(E_{1}+E_{2}\right) * \cos \left[\left(k \theta_{3}\right)\right]\right]$

If the voltage magnitude (for example: $\mathrm{E}_{1}$ ) of one of the sources varies then the sensitivity equation can be given as shown in equation 14 .

\section{$\left(\delta V_{1} k\right) /\left(\delta E_{1} 1\right)=4 / \pi *\left[\cos \llbracket\left(k \theta_{1} 1 \rrbracket\right)+\cos \left(k \theta_{1} 3\right)\right]$}

The magnitudes higher order harmonics is given by the equations 15 to 19 .

$$
\left(\delta V_{1} 1\right) /\left(\delta E_{1} 1\right)=4 / \pi *\left[\cos \llbracket\left(\theta_{1} 1 \rrbracket\right)+\cos \left(\theta_{1} 3\right)\right]
$$

$$
\left(\delta V_{\downarrow} 3\right) /\left(\delta E_{\downarrow} 1\right)=4 / \pi *\left[\cos \llbracket\left(3 \theta_{\downarrow} 1 \rrbracket\right)+\cos \left(3 \theta_{\downarrow} 3\right)\right]
$$

$$
\left(\delta V_{1} 5\right) /\left(\delta E_{1} 1\right)=4 / \pi *\left[\cos \left[\left(5 \theta_{1} 1 \rrbracket\right)+\cos \left(5 \theta_{1} 3\right)\right]\right.
$$

$$
\left(\delta V_{1} 7\right) /\left(\delta E_{1} 1\right)=4 / \pi *\left[\cos \llbracket\left(7 \theta_{1} 1 \rrbracket\right)+\cos \left(7 \theta_{1} 3\right)\right]
$$

$$
\left(\delta V_{1} 11\right) /\left(\delta E_{1} 1\right)=4 / \pi *\left[\cos \llbracket\left(11 \theta_{1} 1 \rrbracket\right)+\cos \left(11 \theta_{1} 3\right)\right]
$$

If $E_{2}$ is varied the sensitivity equation can be given as shown in equation .20 ,

$\left(\delta V_{1} k\right) /\left(\delta E_{1} 2\right)=4 / \pi *\left[\cos \llbracket\left(k \theta_{1} 2 \rrbracket\right)+\cos \left(k \theta_{1} 3\right)\right]$

The magnitude of higher order harmonics is given by the equations 21 to 25 and the change in the magnitude of harmonics is shown in table -II.

$$
\left(\delta V_{1} 1\right) /\left(\delta E_{1} 2\right)=4 / \pi *\left[\cos \llbracket\left(\theta_{1} 2 \rrbracket\right)+\cos \left(\theta_{1} 3\right)\right]
$$

$\left(\delta V_{1} 3\right) /\left(\delta E_{1} 2\right)=4 / \pi *\left[\cos \llbracket\left(3 \theta_{1} 2 \rrbracket\right)+\cos \left(3 \theta_{1} 3\right)\right]$

$\left(8 V_{1} 5\right) /\left(\delta E_{1} 2\right)=4 / \pi *\left[\cos \llbracket\left(5 \theta_{1} 2 \rrbracket\right)+\cos \left(5 \theta_{1} 3\right)\right]$

$\left(8 V_{\downarrow} 7\right) /\left(\delta E_{\downarrow} 2\right)=4 / \pi *\left[\cos \llbracket\left(\llbracket 7 \theta \rrbracket_{\Downarrow} 2 \rrbracket\right)+\cos \left(7 \theta_{\Downarrow} 3\right)\right]$

$\left(\delta V_{1} 11\right) /\left(\delta E_{1} 2\right)=4 / \pi *\left[\cos \llbracket\left(11 \theta_{1} 2 \rrbracket\right)+\cos \left(11 \theta_{1} 3\right)\right]$

Where, $\theta_{1}, \theta_{2}, \theta_{3}$ represents the switching angles of the various levels of the output voltage.

TABLE II : CHANGE IN MAGNITUDE OF HARMONICS (THEORETICAL VALUE)

\begin{tabular}{|l|l|l|l|l|l|}
\hline $\begin{array}{l}\text { Chan } \\
\text { ge in } \\
\text { DC } \\
\text { sourc } \\
\text { e }\end{array}$ & $\begin{array}{l}\text { Fund } \\
\text { Com } \\
\text { pone } \\
\text { nt }\end{array}$ & $\begin{array}{l}\mathbf{3}^{\text {rd }} \\
\text { order }\end{array}$ & $\mathbf{5}^{\text {th }}$ & $\begin{array}{l}\mathbf{7}^{\text {th }} \\
\text { order }\end{array}$ & $\begin{array}{l}\mathbf{1 1}^{\text {th }} \\
\text { order }\end{array}$ \\
\hline$\frac{\delta V_{k}}{\delta E_{1}}$ & 1.071 & -0.886 & - & -0.442 & - \\
\hline$\frac{\delta V_{k}}{\delta E_{2}}$ & 0.700 & -1.54 & 1.209 & -0.1676 & 0.005 \\
& & & & & 7 \\
\hline
\end{tabular}


IOSR Journal of Engineering

Change in magnitude of the DC sources and the impact of the change in magnitude of the source in the peak value of the higher order harmonics is shown in Table-II and the simulation results are given in Table -III. $\left(\theta_{1}, \theta_{2}\right.$ and ${ }_{\theta 3}$ have been taken as $39.651^{\circ}, 61.388^{\circ}$ and $85.918^{\circ}$ respectively). It can be concluded that the $5^{\text {th }}, 7^{\text {th }}$ and the $11^{\text {th }}$ order harmonics are greatly affected, due to the changes in the magnitudes of the DC sources used.

\section{TABLE -III : SIMULATION RESULTS}

\begin{tabular}{|l|l|l|l|l|l|}
\hline $\begin{array}{l}\text { Change } \\
\text { in DC } \\
\text { source }\end{array}$ & $\begin{array}{l}\text { Fund } \\
\text { Com } \\
\text { pone } \\
\text { nt }\end{array}$ & $\mathbf{3}^{\text {rd }}$ & $\begin{array}{l}\mathbf{5}^{\text {th }} \\
\text { ord } \\
\text { er }\end{array}$ & $\begin{array}{l}\mathbf{7}^{\text {th }} \\
\text { ord } \\
\text { er }\end{array}$ & $\begin{array}{l}\mathbf{1 1}^{\text {th }} \\
\text { ord } \\
\text { er }\end{array}$ \\
\hline $\mathrm{V}_{\mathrm{dc}}=50$ & 117.9 & 8.77 & 0.8 & 1.4 & 1.1 \\
$\mathrm{~V}, 100 \mathrm{~V}$ & 9 & & 9 & 1 & 7 \\
\hline $\mathrm{V}_{\mathrm{dc}}=55$ & 120.8 & 9.75 & 0.9 & 1.5 & 1.2 \\
$\mathrm{~V}, 100 \mathrm{~V}$ & 3 & & 0 & 7 & 6 \\
\hline $\mathrm{V}_{\mathrm{dc}}=50$ & 122.4 & 8.73 & 0.9 & 1.4 & 1.1 \\
$\mathrm{~V}, 105 \mathrm{~V}$ & 8 & & 3 & 0 & 8 \\
\hline
\end{tabular}

\section{SIMULATION RESULTS}

Simulation was carried out in order to make sure the computed switching angles were actually eliminating the desired harmonics while at the same time controlling the value of the fundamental. SIMULINK, an extension to MATLAB, was used to perform the simulations of the multilevel inverter. Harmonic Elimination has been employed to eliminate the $5^{\text {th }}$ and the $7^{\text {th }}$ order harmonics 12]. The seven level phase voltage and the line voltage obtained by incorporating the proposed strategy are shown in the Figs. $3 \& 4$ respectively. The frequency spectrum of the linevoltage is shown in Fig.5.

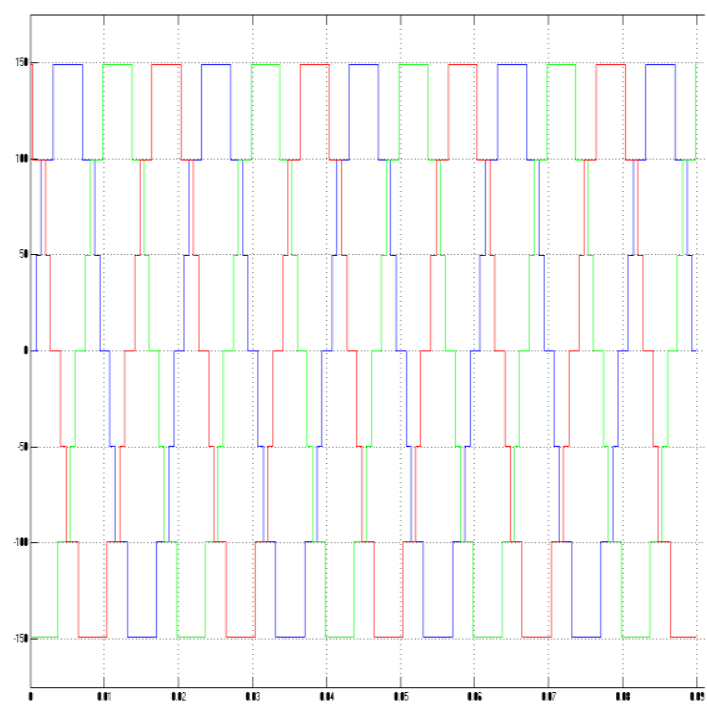

Fig.3 Phase voltage of 3-phase MLI using harmonic elimination scheme

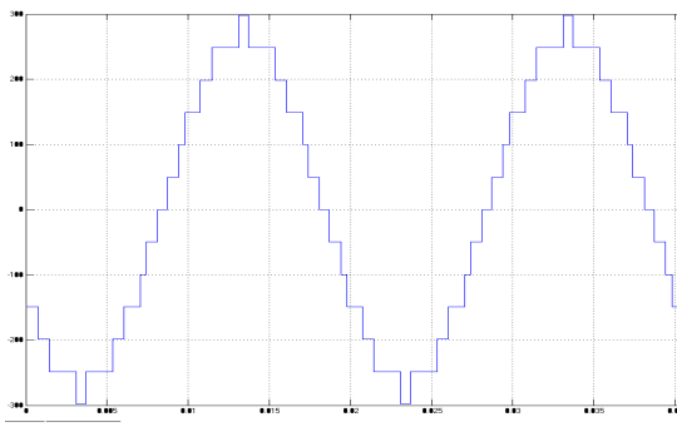

Fig.4.a Line voltage AB of 3-phase MLI

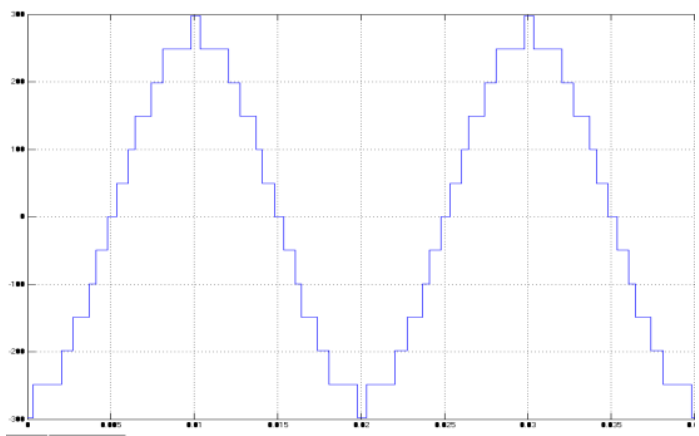

Fig.4.b Line voltage BC of 3-phase MLI

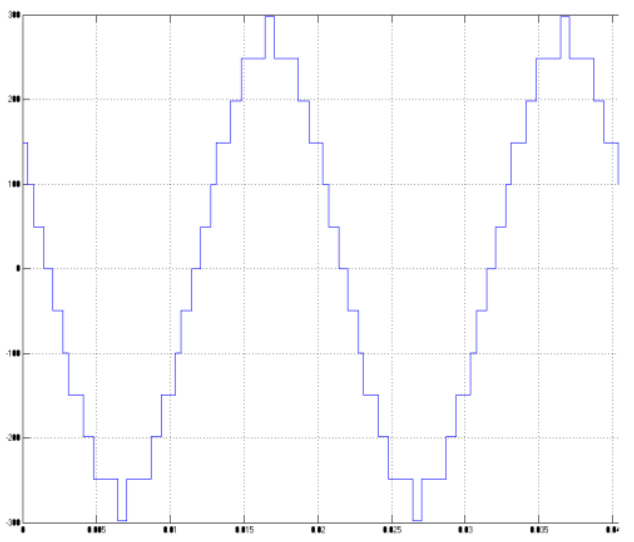

Fig.4.c Line voltage CA of 3-phase MLI

Figure 4. illustrates the line voltages measured at the output of the multilevel inverter. Figure 5 provides the corresponding FFT of the line AB output voltage. 


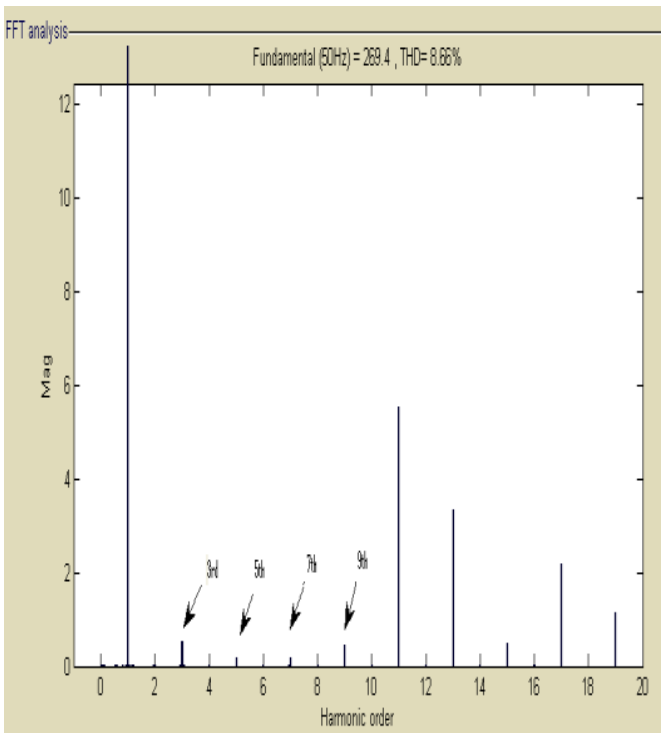

Fig.5 FFT of line voltage AB for ma $=1.2$

th th

From Fig.5, that the magnitudes of the 5 and 7 harmonics are quite small. One reason they are not precisely zero is the battery voltages are not exactly equal to one another. Also there may be some quantization error. The corresponding voltage THD is $8.66 \%$. The three switching angles for an asymmetric seven level inverter are calculated for the different modulation index and the graph is plotted with switching angles against modulation index. Figure.6 provides switching angles of 7-level multilevel inverter for the different modulation index and the Fig .7 illustrates the corresponding THD for the different modulation index.

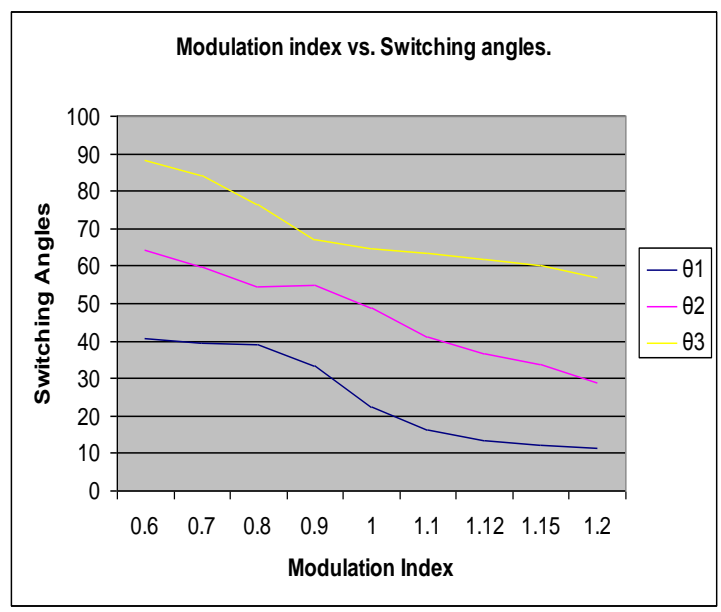

Fig. 6 Switching angles for 7-level multilevel inverter

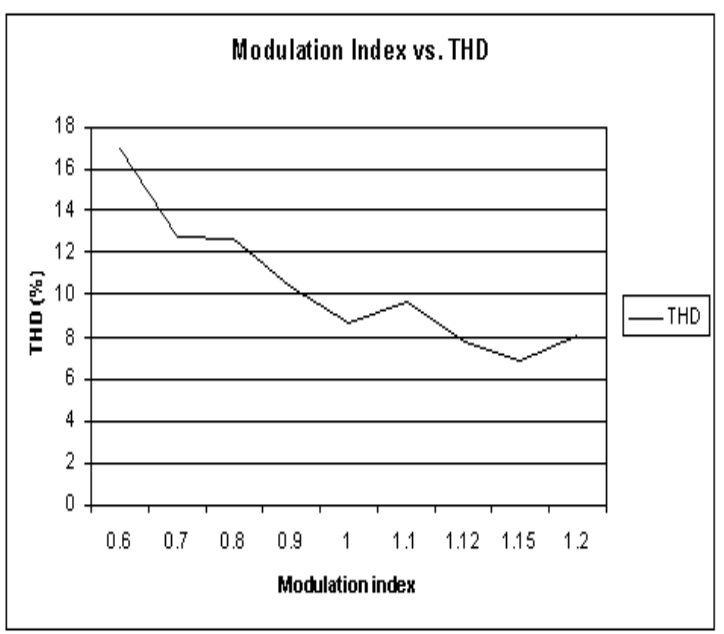

Fig.7 Voltage THD from 7-level multilevel Inverter

\section{EXPERIMENTAL RESULTS}

A prototype of a three-phase, seven-level (three dc sources) cascaded H-bridge multilevel inverter was developed with power MOSFETs having voltage rating of $600 \mathrm{~V}$ and current rating of $5 \mathrm{~A}$. Rechargeable batteries were used for the separate DC sources. With a resistive load connected to the output, measurements were taken for the output voltage and the experimental seven-level output is shown in Fig.8.

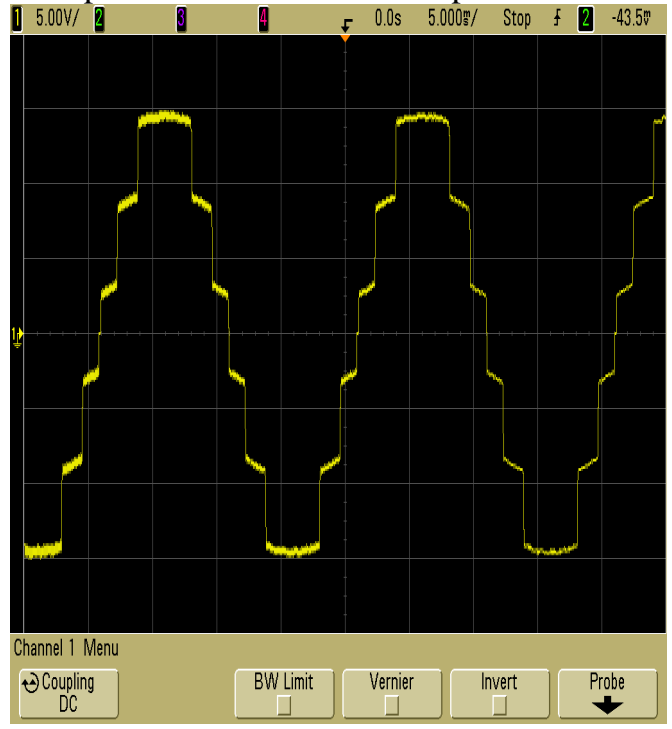

Fig.8 Experimental seven-level output voltage waveform for asymmetric cascaded MLI

\section{CONCLUSION}

This paper presented a three-phase cascaded multilevel inverter with unequal DC sources. A procedure to selectively eliminate certain harmonics in a multilevel inverter utilizing the fundamental switching scheme has been discussed. The effect of DC source equalization has 
IOSR Journal of Engineering

June. 2012, Vol. 2(6) pp: 1313-1319

been studied. Simulation results and experimental studies have been presented which clearly shows the selective harmonic elimination reduces the harmonic distortion in the output.

\section{REFERENCES}

1. Jose Rodriguez, Jih-Sheng Lai, Fang Zheng Peng 'Multilevel Inverters: A Survey of Topologies, Controls and Applications', IEEE Transactions on Industrial Electronics, Vol.49, No.4, pp.724-738, 2002.

2. L. M. Tolbert, F. Z. Peng, and T. G. Habetler, "Multilevel converters for large electric drives," IEEE Transactions on Industry Applications, vol. 35, no. 1, pp. 36-44, Jan./Feb. 1999.

3. J. N. Chiasson, L. M. Tolbert, K. McKenzie, Z. Du, "Real-Time Computer Control of a Multilevel Converter using the Mathematical Theory of Resultants," Proceedings of the Electric machines Conference, August 18-21, 2002.

4. J. Chiasson, L. M. Tolbert, K. McKenzie, and Z. Du, "Control of a multilevel converter using resultant theory," IEEE Transactions on Control System Technology, vol. 11, no. 3, pp. 345-354, May 2003.

5. Manjunatha Y.R, Sanavullah M.Y 'Harmonics Elimination on Multilevel Inverters with Two Unequal Voltage Batteries', Asian Power Electronics Journal, Vol.2, No.3, pp.153-157, 2008.

6. J. Chiasson, Neon M. Tolbert and Zhong Du, "Active Harmonic Elimination for Multilevel Converters" IEEE transactions on Power Electronics, Vol. 21, No.2, March 2006.

7. S. Wolfram, Mathematica, A System for Doing Mathematics by Computer, Second Edition. AddisonWesley, 1992.

8. Ahmadi, D, Jin Wang, 'Selective Harmonic Elimination for Multilevel Inverters with Unbalanced DC Inputs', IEEE Conference on Vehicle Power and Propulsion, pp.773-778, 2009..

9. Deepa, K, Savitha, P, Vinodhini, B. 'Harmonic Analysis of Modified Cascaded Multilevel Inverter, $1^{\text {st }}$ International Conference on Electrical Energy Systems, pp.92-97, 2011.

10.Jingang Han, Peng Yao, Liwei Zhou, Xinyuan Tan, Tianhao Tang, 'Selective Harmonic Elimination for an Asymmetrical Multilevel Converter', IEEE Industrial Symposium on Industrial Electronics, pp.993-997, 2007.

11. Muthuramalingam A, Balaji M, Himavathi S, 'Selective Harmonic Elimination Modulation for Multilevel Inverters', India International Conference on Power Electronics, pp.40-45, 2006.

12. Naeem Farokhnia, Hadi Vadizadeh, Seyyed Hamid Fathi, Seyyed Hamid Fathi , "Calculating the Formula of Line-Voltage THD in Multilevel Inverter with Unequal DC Sources', IEEE Transactions on Industrial Electronics, Vol.58, No.8, pp.3359-3372, 2011. 